\title{
The Impact of Research Funding on Scientific Outputs: Evidence from Six Smaller European Countries
}

\author{
Abdullah Gök1, John Rigby² and Philip Shapira ${ }^{3}$
}

\author{
This is a preprint of an article accepted for publication on 13/08/2014 in \\ Journal of the Association for Information Science and Technology (C) 2014
}

(Association for Information Science and Technology).

\begin{abstract}
Please cite as "Gök, A., Rigby, J. \& Shapira, P. (forthcoming). The Impact of Research Funding on Scientific Outputs: Evidence from Six Smaller European Countries. Journal of the Association for Information Science and Technology. doi: 10.1002/asi.23406".
\end{abstract}

\begin{abstract}
We investigate the relationships between the citation impacts of scientific papers and the sources of funding which are acknowledged as having supported those publications. We examine several relationships potentially associated with funding including first citation, total citations and the chances of becoming highly cited. Furthermore, we explore evidence on the links between citations and types of funding by organization and also with combined measures of funding. In particular, we examine the relationship between funding intensity and funding variety and citation. Our empirical work focuses on six small advanced European economies, applying a zero inflated negative binomial model to a set of more than 240,000 papers authored by researchers from these countries. We find that funding is not related to the first citation but is significantly related to the number of citations and top percentile citation impact. Additionally, we find that citation impact is positively related to funding variety and negatively related with funding intensity. Finally there is an inverse relationship between the relative frequency of funding and citation impact. The results presented in the paper raise insights for the design of research programs and the structure of research funding and for the behavior and strategies of researchers and sponsoring organizations.
\end{abstract}

Keywords: research funding, citation impact, scientific output

\footnotetext{
${ }^{1}$ Manchester Institute of Innovation Research, Manchester Business School, University of Manchester; abdullah.gok@manchester.ac.uk

${ }^{2}$ Manchester Institute of Innovation Research, Manchester Business School, University of Manchester; john.rigby@mbs.ac.uk

${ }_{3}$ Manchester Institute of Innovation Research, Manchester Business School, University of Manchester and School of Public Policy, Georgia Institute of Technology; pshapira@mbs.ac.uk
} 


\section{Introduction}

In today's era of globalization, scientific researchers work increasingly in collaboration, creating teams that may be temporal but which are made up of a wide range of participants, often from several countries, and frequently supported by funding from a wide range of sources. This internationalization of science reflects desires to draw on the best available expertise wherever it may be found and the existence of resources with which this can be achieved Patterns of international science collaboration are also influenced by historical, political, cultural, labor mobility, research evaluation, and other innovation system factors, all of which mediate how trans-boundary research collaboration develops.

In developing their international collaborative relationships, scientists can be viewed as a forming a complex and diverse community that not only draws on resources but also develops strategies and routines to pursue answers to research questions, and doing so in a mix of collaborative and competitive modes. Scientists particularly in the natural sciences must obtain and match the physical and financial resources to their own capacities to the scientific challenge they face. A key aspect of this challenge, in addition to the selection of questions and research methods, what is thought to be the core of scientific expertise, is obtaining the resources with which to work. The process of securing resources is not neutral in its impact on science - indeed, as Stephan (2012) argues, economics has a powerful influence in shaping science.

This paper focuses on an important aspect of how economics influences science - examining how research funding sponsorship is associated with citation impact. The use of funding acknowledgement data, now increasingly available, and to a degree of detail not previously available, makes it possible for us to investigate the relationship between the citation impact of publications and the funding which is acknowledged as having supported those publications. The paper brings a new approach to the detailed examination of the link between inputs and outputs and employs newly available funding acknowledgement data from the Web of Knowledge which has only been available from August 2008. We focus upon six small advanced European nations. By virtue of their relatively small size, researchers in these countries are attracted to seek research partners in other countries, although as we will see, with varying propensities and effects. Researchers in all of these countries also have the opportunity to access supra-national research funding through the European Union - funding that invariably requires multi-national research teams. We report on differences in citation impact between the countries and in terms of source of funds, and other characteristics of the funding which is acknowledged as having supported the research. The study exploits the possibilities of considering the influence on citation impact of many levels of funding provision as, in the 
European Union, research performers can draw on a wide range of funding opportunities at the following scales: regional, national, international bi- and tri-lateral agreements, and supranational, i.e. EU levels, and international organizations.

The study uses a zero-inflated negative binomial approach to model specification to better characterize the role played by the different types of funding in 242,406 papers from Belgium, Denmark, the Netherlands, Norway, Switzerland and Sweden. The analysis also gives insight into the relationship between national (Member State) and European Union funding and the impact of papers supported.

The paper begins with a discussion of the literature on the factors affecting citation. Our review looks specifically at how the link between research outcomes and inputs has been conceptualized and the key role of grant awarding bodies. Drawing from this literature we propose a number of aspects of the relationship between funding organizations and impact to test empirically. We introduce our model describe its key features and then apply it to our data set. We then review the results of the analysis and consider the implications. 


\section{A Review of Literature}

The study reported here has been developed to exploit newly available data from the Web of Science in order examine a key issue in science policy, namely how does the way papers are funded relate to their citation impact. Our aim has been to consider the link between funding and citation and also to pay attention to the identity of funding organizations to determine whether certain funding bodies and also types of funding body are associated with higher citation impact. A priori, it might also seem that a combination of funding instruments by origin and type of funding body might be associated with citation impact of papers. Our review of literature has been undertaken to develop our understanding of what is known about the link between funding, research and citation impact.

\subsection{The Research Process}

Within the literature that considers science and its outputs, an important distinction can be seen between studies that assume a system with inputs and outputs, and studies that pay attention to the processes involved and that lead from inputs, whether or people or other resources, to outputs, in terms of papers, and further use of the knowledge, such as citation, and beyond that to technology, economic and social development. The second of these groups of studies is more "internalist" in its investigation in that it includes as a units of analysis aspects of the research process. Nevertheless, both types of studies have contributed materially to the development of our understanding of how scientific organizations convert and use resources to outputs and impact, of various kinds. A number major studies which explicitly connect input and output issues to notions about how the process of knowledge production as a whole operates (Etzkowitz \& Leydesdorff, 1997; Gibbons et al., 1994) should be mentioned although our study is focused at a smaller level where there is now some work that has examined the issue of research process using small data sets (Rigby, 2009, 2013).

\subsection{Evaluation Literature}

Within the evaluation literature, studies have been generally been focused upon output, outcome and impacts and have employed quantifying approaches that place priority upon economic impacts. There are a number of important studies that debate the nature of the impacts and the best way to perform such evaluations (Kostoff, 1993; Kreilkamp, 1971; Sherwin \& Isenson, 1967).

\subsection{Science, technology and policy studies and factors affecting impact}

Research has also been conducted in a wide range of academic disciplines including economics, management, business, social studies, evaluation and library and information science to broaden understanding of the many factors that influence research and its outputs, outcomes and impacts of research. Such approaches have made the assumption that the study of science should 
emphasize the social contexts in which research is done (Whitley, 2000) and a range of methods have been applied, both qualitative and quantitative.

These studies have focused on a number of aspects and one of which, collaboration, has attracted great attention (Katz \& Hicks, 1997; Katz \& Martin, 1997). Interest in the research process is that greater understanding gives policy makers some insights that they can use to design and adapt their research funding programs to make them more effective. The question of design has been dealt with by many writers who have covered a multitude of aspects, generally speaking at system, meso, and micro levels. Large scale design issues have been examined and focus on key assumptions of the system (Bleda \& del Rio, 2013; Martin \& Scott, 2000; Nemet, 2009), on the need for indicators to control and understand impact, and on the co-evolution of policy and theory (Grupp \& Mogee, 2004; Mytelka \& Smith, 2002), while large scale problems and how to cope with them are now being considered again with adoption of such policies by the European Union (Mowery, Nelson, \& Martin, 2010) which seems them "new grand challenges; but other studies have looked at the more detailed level at the relations between actors in the innovation process, including links between industry and the universities (Clarysse, Tartari, \& Salter, 2011; Kolodny, Stymne, Shani, Figuera, \& Lillrank, 2001; Marin \& Siotis, 2008)

Other important contributions within the literature that has examined factors affecting impact, and mainly citation include (Baldi, 1998; Haslam et al., 2008; Heinze, Shapira, Rogers, \& Senker, 2009). Recently, a subject field study on the nanotechnology area by Didegah and Thelwall (2013) has reviewed a large body of research in which the link between the characteristics of research and its citation impact was studied. The papers reviewed examined a range of links between the research and its citation, focusing on a) the contextual factors of the research published (journal identity and type, the field of research), b) "producer" characteristics (count of and identities of authors and institutions involved in the research, countries - identify and counts, c) key aspects of the text (type of paper, impact of references used, count and recentness of references), and d) the specific content of the paper (particularly the methodologies of the paper). Didegah and Thelwall's study confirmed a number of hypotheses about factors which influence citation such as journal categories and impact factor which are not perhaps surprising, but their work has also shown up other factors that are known in the field of nanotechnology research to be important but not necessarily in other fields such as the count of references. This study also reported a small effect whereby the count of institutions was linked to increased impact.

\subsection{Attention to the role of funding source}

Over the course of the last three decades, there has been a number of studies conducted to examine the link between funding and research topic coverage and focus, which were conducted to inform the research policy of particular funding bodies. The relatively early studies in this area, which 
have often assumed that the papers reported by researchers to funding bodies as resulting from particular grants were the exclusive product of that research funding, comprise topic and field studies (Lewison, 1994, 1998; Lewison, Grant, \& Jansen, 2001; Lewison \& Markusova). Such studies have primarily used sets of publications which grantees have notified as resulting from their awards from particular funding bodies. Studies of research impact have also not generally been able to relate impact or the performance of research to the type of grant although a small number of studies have attempted to focus on this precise issue ((Rigby, 2009) and more recently, (van den Besselaar \& Sandstrom, 2013).

The concerns of this early work, which were to investigate the link between impact and the identity of the funding body (Lewison, 1994, 1998, 2003; Lewison \& Dawson, 1998), are now being taken up again because of the availability of new data from Thomson Reuters, providers of the Web of Science database, which now includes funding acknowledgement data in its main information products (Lewison, 2009). This new information, which comes from a more extensive indexing process, makes it possible to undertake far more expansive investigations of research funding and the relationships between funding and other properties of a published work, including citation, the major measure of impact. Shapira and Wang (2010), in an early application of the Web of Science funding acknowledgement data, examined cross-border patterns of sponsorship in nanotechnology research and relationships to research impacts. They used data-mining techniques on the raw funding acknowledgement data to distinguish sponsoring organizations (see also Wang and Shapira, 2011). Others (for example, Wang et al., 2012; Costas \& van Leeuwen, 2012; Sirtes, 2013) have also examined and analyzed the Web of Science funding acknowledgements data, including using it to ascertain types and sources of funding and relationships with collaboration in publications and impact. Rigby $(2011,2013)$ has highlighted the issues involved in the use of this funding acknowledgements data, and also the scope for comparing research funders and the extent of simultaneous funding. The new data can be used to shed light on the extent of double-funding where funding bodies find that they might be paying for work that other grants have already covered, an issue which has raised concerns amongst funding bodies and the extent of which is difficult to assess (Rigby \& Julian, 2013).

This burgeoning line of work on research sponsorship addresses, in part, a series of concerns and interests of public and private funding bodies, as well of universities, scientists, government and other stakeholders. These include ensuring that supported research leads to work with high scientific quality and relevance to organizational missions and strategic goals, supports leading researchers, is used to investigate leading or promising topics, and is made available to those who have track records in attracting resources to conduct research (Yegros-Yegros \& Costas, 2013). The new research on the linkages between citation and factors which affect it, now can incorporate information related to the sources and characteristics of funding. 
Funding acknowledgements data was first made available for papers indexed in the Web of Science's Science Citation Index (SCI) and published since in mid-2008. The majority of these recent papers contain funding acknowledgements information in their SCI index records. For example, of the more than 1.23 million SCI papers published in 2013, about 0.83 million (67.3\%) contain funding acknowledgements data. There are variations by country of authorship. In 2013, for the two countries producing the highest number of papers, 73.7\% of US SCI papers included funding acknowledgements data, rising to $86.4 \%$ for Chinese SCI papers. For Germany, Japan, and the UK, who are the next largest producers of scientific papers, funding acknowledgements data was included for $68.6 \%, 63 \%$, and $72 \%$ of their SCI papers respectively. ${ }^{1}$ There are of course limitations with the available data (as also noted in Wang and Shapira, 2011; Sirtes, 2013). For example, the current funding acknowledgements data in the Web of Science does not give the precise amounts of money allocated within a grant on a systematic basis. Variations in the spelling, abbreviation, and acronyms for the same funding organization names and programs require data cleaning and careful consolidation. Institutional "core" funding, where resources are allocated internally within research performing organizations without expectations of acknowledgement, is not effectively captured by the funding acknowledgements field with its focus on awards from external funding bodies. It is likely that a significant portion of the papers that do not acknowledge funding were supported through institutional core finding. The order of the funders acknowledged may or may not reflect its importance to the researchers who produced the publication or the amount of funding made available. Not all funding awards received by researchers may be acknowledged in a particular publication, notwithstanding requirements by major funding bodies that funding acknowledgements must be listed in publications (see NSF, 2001, p34; ERC, 2012, p18; EPSRC, 2014, p32). In some cases, funding may be "overacknowledged" to gain credit with sponsors, even though a particular named source may be peripheral to the published research.

Despite these caveats, the scale and detail of the funding acknowledgements data available in the Web of Science, and reported by a majority of SCI papers, provides an important information resource to probe questions related to research funding sponsorship. In particular, this data offers additional opportunities to investigate links between research funding and impact. The extensiveness of the funding acknowledgements data allows large scale field and country comparisons, helping us to extend our knowledge of the quasi-market where researchers compete nationally and globally to obtain funds to conduct the research they believe is important and funders compete for the best scientists to whom to direct resources to funding body priorities.

\footnotetext{
1 Authors' analysis of funding acknowledgements data in Science Citation Index, Web of Science, for articles published in 2013 ( $\mathrm{N}=1,232,692)$, accessed via the University of Manchester Library (July 31, 2014).
} 
Examination of the links between funding and citation is a further window to probe and understand the interrelated processes of sponsorship, performance, and outcomes in the world of scientific research. In this paper, we are especially interested in the role of a particular kind of research funding - supra-national sponsorship, as exemplified by the major research programs of the European Union - and how this research funding compares with other kinds of sponsorship, such as provided by national research funding agencies, corporations, or non-governmental bodies. The next section further explains our supra-national context.

\subsection{The European Union as a source of research funds}

The European Union (EU) - with 28 member states as of 2014 - is the world's largest supranational economic bloc, accounting for more than one-quarter of the world's economic output. EU R\&D spending reached almost $€ 270$ billion in 2012 , of which $54.9 \%$ was sponsored by business enterprise, $33.4 \%$ by government, with the balance derived from higher education, private nonprofits, and other sources. ${ }^{2}$ The bulk of governmental R\&D funding in Europe is sourced at the national level, with a portion also from regional authorities. However, a growing amount of funding for research and innovation is allocated at the European level, through several major EU mechanisms. Research funding made available through the EU's multi-year Framework Programmes rose progressively from $€ 3.75 b$ for the $1^{\text {st }}$ Framework Programme (1984-1988) and $€ 17.88$ billion for the $6^{\text {th }}$ Framework Programme (2002-2006) to more than $€ 50$ billion (2007-2013) in the 7th Framework Programme for Research, Technological Development and Demonstration Activities (FP7). (BIS 2011) Nearly €80 billion is allocated to the successor research and innovation program, Horizon 2020, from 2014 through to 2020. ${ }^{3}$ The EU's Cohesion Policy Structural Funds made available a further $€ 50$ billion to R\&D and innovation (2007-2013), including funds for research and technology development infrastructure and centers, researchoriented firms, and technology transfer. Other smaller EU sources for research and innovation include the Competitiveness and Innovation Framework Programme, the Euratom Framework Programme, and agricultural and fisheries funds (EU 2012).

the Structural Funds and the Cohesion Fund within the Cohesion policy; the European Agricultural Fund for Rural Development and the European Fisheries Fund within the Rural development policy and the Common Fisheries Policy.

\footnotetext{
2 Total intramural R\&D expenditure (GERD) by sectors of performance; and Key indicators - GERD by source of funds, 2012 data. Statistics on Research and Development, Eurostat, http://epp.eurostat.ec.europa.eu/portal/page/portal/science_technology_innovation/data/database, accessed August 4, 2014.
}

${ }^{3} \mathrm{http}: / /$ ec.europa.eu/programmes/horizon2020/en/what-horizon-2020, accessed August 4, 2014. 
EU investment in research and innovation goes towards a range of purposes, including scientific research, researcher mobility, scientific and technological infrastructure, and knowledge dissemination. Within the literature on the role of the EU and its programs in supporting research and whether such programs have added value, there have been a number of important studies but few systematic large scale bibliometric studies. There is broad discussion about the effectiveness of these investments (see, for example, BIS 2011). An early study by Georghiou and Metcalfe examined the impact of the Framework Programme (FP) on industrial competitiveness (Georghiou \& Metcalfe, 1993). Recent work on the impact of the European Union's Framework Programme includes that by Arnold (E. Arnold, 2012) although this does not use bibliometric methods. A number of other studies that have looked at the Framework Programmes (including J. G. Arnold \& Fohrer, 2005; Bayona-Saez \& Garcia-Marco, 2010; Cassi, Corrocher, Malerba, \& Vonortas, 2008; Jennings, 2012; Kleijn \& Sutherland, 2003; Laredo, 1998; Lewison, 1994; Noyons, Teigland, Schenkel, \& Maier, 2009). The European Research Council (launched in 2007) has been subject to investigation but researchers have tended to examine its processes rather than its research impacts (Luukkonen, 2012; Neufeld, Huber, \& Wegner, 2013; Scherngell et al., 2013; Thomas \& Nedeva, 2012). In the context of our own investigations of the linkages between funding sponsorship and research outputs, we are particularly interested in how EU sponsorship affects research quality and impact. However, to our knowledge, comparisons with Member State and other sources of funding have to our knowledge not been conducted. For reasons we discuss in detail later, research papers typically have more than one funding source, so simple unique attributions to single sources are not readily made. Still, we are curious to understand the incremental research impacts of adding supranational European funding to the mix of sources that European researchers use to sponsor and support the work which is reported in their scientific publications. The availability of WoS SCI paper funding data should enable us to further probe this particular topic.

\section{Research Questions and Hypotheses}

A number of important new questions are emerging which we believe our study is able to shed light on given the availability of new data about the origin of funding for research. There are three main areas where our analysis of this new data may provide further insight into questions where there has been some work but where there remains uncertainty.

The first question is what is the link between funding (evidenced by funding acknowledgements) and citation impact? Our hypothesis (H1) is that research funding is related with citation impact. To address this, we examine not only the links between the existence of funding and citation but also the link between funding and high levels of citation. 
Our second question is how does the type and level of funding have influence on citation impact?

We are interested in the differential influences of funding from government, private, and other sources and also how the hierarchical level (including national, international, and supranational funding) and mix of funding is associated with citation. Our hypothesis (H2) is that there is a hierarchy of research funding sources in terms of citation impact.

The third question is how do the internal dynamics of research funding allocation influence citation? Our hypothesis (H3) is that the intensity and variety of research funding influences citation impact. To address this, we construct and test measures that use funding acknowledge data to probe inside the resourcing and management of the research process.

The next sections presents the approach and method used to investigate these hypotheses.

\section{Data and Methods}

\subsection{Data Source}

To examine our research questions, we sought to develop a data set of publications from a set of countries which are comparable with one another and where research performers have access to funding at many levels. We developed a dataset composed of scientific publications by authors from Belgium (BE), Denmark (DK), Netherlands (NL), Norway (NO), Switzerland (CH) and Sweden (SE). These six countries have populations ranging from 5.1 to 16.8 million, with gross domestic product per capita ranging from 1.3 to 2.9 times the European Union average. ${ }^{4}$ These six countries were selected on the basis of three criteria. First, all six represent advanced but relatively small research systems in Europe where researchers frequently seek international partners. Second, the research funding systems in these countries are relatively analogous, which adds to the comparability. Finally the relatively small size of these six countries makes the analysis conducted in this paper more manageable by optimizing the amount of data cleaning involved and managing the complexity of funding systems.

The dataset includes only articles as they are the main form of scientific publications and constitute a single class of publication. This research takes advantage of the semi-structured funding acknowledgements information provided in the Science Citation Index (SCI) of the ISI Web of Science. Publications in the Social Science Citation Index (SSCI) and Arts and Humanities Citation Index (AHCI) as these indices do not yet include funding information. The dataset includes articles published in the period January 2009 - December 2011 (36 months). Although funding acknowledgments data was first accessible in SCI from mid-2008, we do not include any 2008 publications as full-year coverage is not available. The data was downloaded in 2012,

\footnotetext{
42013 data, calculated from Eurostat statistical tables for population and gross domestic product. http://epp.eurostat.ec.europa.eu/portal/page/portal/eurostat/home (accessed August 6, 2014).
} 
allowing up to a 4-year window for citations to accrue. Non-English language publications are excluded, but these only comprise about one percent of the SCI data. The focus on Englishlanguage publications facilitates cross-comparability between the six countries. The total number of publications included in our analysis is just under a quarter of a million $(242,406)$.

\subsection{Data Cleaning and Variables Used}

The funding organization data reported in the Web of Science is derived from the funding acknowledgements listed in the underlying publications. The available data is mostly arranged in formed or semi-formed sentences. We use VantagePoint text-mining software to automate the process of extracting organizations from the acknowledgements text and to undertake cleaning and merging. This is not a seamless process, and it requires iteration and review to minimize ambiguity. Included in the tasks of cleaning are separating multiple funders from within the funding organization field, merging variations in spelling or abbreviations of the same funder, isolating unintelligible funder names, and finally categorizing identified funding organizations. We categorize sponsors, from the perspective of the country of publication, into the following four classifications:

- National Public Funders (f_national): Public, governmental and quasi-public organizations sponsoring research within their own country, including research councils, ministries and academies.

- International Public Funders (f_international): Nationally-based public, governmental and quasi-public funders who sponsor research in other countries. For example, a publication co-authored by a researcher in country A may acknowledge funding received, as part of international collaborative research, from a national research council in country B.

- European Union (EU) Funders (f_eu): research funding provided through one or more of the mechanisms and institutions of the EU, such as the Sixth or Seventh Framework Programmes (FP6 or FP7), Structural Funds (e.g. European Regional Development Fund), or the European Research Council.

- Non-Governmental and Corporate Funders (f_private): This category includes nongovernmental funders including independent (private non-profit) foundations as well as corporate funders such as pharmaceutical companies. These funders are often, but not always, based in the home country of the research recipient.

As the National Public Funder and International Public Funder categories are defined from the perspective of the country of publication, the data is treated in distinct sub-samples for the six countries. Although Norway and Switzerland are not EU member states, they are both members of the European Free Trade Association (with other EU states) and interact with relevant European initiatives (such as the European Research Area). Both Norway and Switzerland 
participated in (and contributed to) EU research programs during the time period of our study (for example, both were full members of FP6 and FP7 and were recipients of European Research Council awards). ${ }^{5}$

As part of the process of organizing the dataset, we cleaned the country and journal subject category fields of the included papers. We further grouped the country affiliations of both authors and funders by continents (c_europe, $c \_$northamerica, $\left.c \_a s i a, c \_o c e a n i a, c \_a f r i c a, c \_s o u t h a m e r i c a\right)$. Subject categories were grouped into the following six broad non-mutually exclusive sets (using the approach described by Porter and Rafols, 2009, and Rafols, Porter, and Leydesdorff, 2010):

- Biology and Medicine (s_biologyandmedicine)

- Physical S\&T (s_physicalst)

- Computer Sci. and Engineering (s_computersciandengineering)

- Environmental S\&T (s_environmentalst)

- Psychology and (Related) Social Sciences (s_psychologyandsocialsciences)

- Social Sciences ${ }^{6}$ (s_socialsciences)

We also created two composite indicators related to funding. The first, funding intensity ( $f$ intensity), is calculated in order to gauge the relative intensity of funding for a publication. Funding intensity is computed by dividing the number of funders in a paper by the number of authors for each paper.

$$
\text { Funding Intensity } y_{i}=\frac{v_{i}^{k}}{A_{i}^{k}}
$$

where $v_{i}^{k}$ is the vector of funding organizations and $A_{i}^{k}$ is the number of authors for publication $i$ in the country sub-dataset $k$.

The minimum value for this variable is 0 where no funding is reported. Relative to the number of funding organizations, the variable is greater than 0 but small if fewer authors in a paper have funding while its value is higher when more authors of a paper are funded. Around 5\% of the publications in our dataset have more funder organizations reported than the number of authors (i.e. some authors are funded by multiple funders), hence around $5 \%$ of $f_{-}$intensity $>1$ while around $95 \%$ _ intensity values ranges between 0 and 1 . This variable is standardized to range between 0 and 1.

\footnotetext{
${ }^{5}$ Following the February 2014 Swiss referendum to limit European Union inward migration, Switzerland's participation in various EU research programs was downgraded or placed in abeyance (see, for example, Jump, 2014). This arose after the research publication period (2009-2011) examined in our study.

${ }^{6}$ Although our dataset does not draw from the Social Science Citation Index, a small number of publications in the dataset are published in interdisciplinary SCI journals that have a secondary category in the social sciences.
} 
Second, a variable to measure the variety of funders of publications is created (f_variety). This variable is calculated by dividing the number of funders by the number of unique funders for each paper.

$$
\text { Funding } \text { Variety }_{i}=\frac{v_{i}^{k}}{\theta(v)_{i}^{k}}
$$

where $\theta(v)_{i}^{k}$ is the vector of unique funding organizations for publication $i$ in the country sub-dataset $k$.

Funding variety ranges between 0 and 1: the variable is zero for a publication where all funded authors are sponsored by a single funder, and takes the maximum value of 1 when all the funders in a paper are unique.

To take account of time, we created (o_yearslapsed) measuring years lapsed since an article's publication. Finally, the dependent variable is measured by the count of the number of times a paper is cited (timescited). A summary of variables used in this analysis is presented at Table 1. 


\begin{tabular}{|c|c|c|}
\hline Variable Name & $\begin{array}{l}\text { Variable } \\
\text { Type }\end{array}$ & Description \\
\hline timescited & Dependent & Number of times a paper receives a citation (count, integer). \\
\hline$f_{-}$national & Independent & $\begin{array}{l}\text { Whether a paper has received funding from national public sources } \\
\text { of the subject country (dichotomous). E.g.: funding from Research } \\
\text { Council Norway for Norway subset. }\end{array}$ \\
\hline f_international & Independent & $\begin{array}{l}\text { Whether a paper has received funding from international public } \\
\text { sources (in respect to the subject country) (dichotomous). E.g.: } \\
\text { funding from NSF (USA) for Norway subset. }\end{array}$ \\
\hline f_eu & Independent & $\begin{array}{l}\text { Whether a paper has received funding from any EU related body or } \\
\text { program (dichotomous). E.g.: funding from FP6 for Norway subset. }\end{array}$ \\
\hline f_private & Independent & $\begin{array}{l}\text { Whether a paper has received funding from any corporate or non- } \\
\text { governmental body (dichotomous). E.g.: funding from Statoil or } \\
\text { Welcome Foundation for Norway subset }\end{array}$ \\
\hline f_intensity & Independent & $\begin{array}{l}\text { (Total number funders for a paper) / (number of authors for a } \\
\text { paper). This variable is standardized to range between } 0 \text { and } 1 . \\
\text { Ranges between } 0 \text { and } 1 \text { (double). } 0 \text { would be least funding } \\
\text { intensive (i.e. no author report funding) and } 1 \text { would be the most } \\
\text { funding intensive (i.e. all authors report funding). Quadratic form } \\
\text { of this variable is also used. }\end{array}$ \\
\hline$f_{-}$variety & Independent & $\begin{array}{l}\text { (Number of unique funders for a paper) / (Total number funders for } \\
\text { a paper). Ranges between } 0 \text { and } 1 \text { (double). } 0 \text { would be least funding } \\
\text { variety (i.e. no author report funding) and } 1 \text { would be the most } \\
\text { funding intensive (i.e. all authors report different funding sources). }\end{array}$ \\
\hline s_biologyandmedicine & \multirow{5}{*}{ Control } & \multirow{5}{*}{$\begin{array}{l}6 \text { subject categories derived from } 243 \text { Web of Science journal } \\
\text { subject categories (dichotomous). Note: one paper may fall into } \\
\text { more than one category, as interdisciplinary journals may be } \\
\text { assigned more than one subject category. }\end{array}$} \\
\hline s_environmentalst & & \\
\hline s_physicalst & & \\
\hline $\begin{array}{l}\text { s_psychologyandsocialsciences } \\
\text { s_computersciandengineering }\end{array}$ & & \\
\hline s_socialsciences & & \\
\hline n_authors & Control & Number of authors. \\
\hline c_europe & \multirow{5}{*}{ Control } & \multirow{5}{*}{$\begin{array}{l}\text { Collaboration with international addressed authors from } \\
\text { particular continents (dichotomous). These variables take value " } 1 \text { " } \\
\text { if there is at least one author in the authors list from the respective } \\
\text { continents. E.g. } c \text { northamerica }=1 \text { if there is an author with a US } \\
\text { address in the author list. }\end{array}$} \\
\hline c_northamerica & & \\
\hline $\begin{array}{l}\text { c_asia } \\
\text { c_oceania }\end{array}$ & & \\
\hline $\begin{array}{l}\text { c_oceania } \\
\text { c_africa }\end{array}$ & & \\
\hline c_southamerica & & \\
\hline o_yearslapsed & Control & $\begin{array}{l}\text { Years lapsed since paper was published (integer). This is used as } \\
\text { an exposure variable in zero inflated negative binomial regression. }\end{array}$ \\
\hline
\end{tabular}

\subsection{Model Specifications}

In our models, the number of citations is our dependent variable and is a count variable with overdispersion (i.e. standard deviation is much higher than mean, see Table 2 for descriptive statistics). This would indicate the use of negative binomial regression models over Poisson regression models. Citations increase over time in general but a certain set of publications do not get any citations at any point. ${ }^{7}$ Our dataset has a significant number of zero-cited papers (see Table 2, percentage of zero-cited papers). Having no citations is an observed phenomenon in scientific publications. This would indicate the use of Zero-inflated Negative Binomial (ZINB) regression (Greene, 2003; Long, 1997; Stata, 2011). Furthermore, Vuong (1989) and zip tests also

\footnotetext{
${ }^{7}$ For instance, around $12 \%$ of the publications published in 1972 by authors from the six countries included in this study had not been cited as of 2013.
} 
point out the preference of ZINB over Negative Binomial regression or Zero-inflated Poisson regression for the type of model we have specified. ZINB regression has increasingly been used in the analysis of citations of publications and patents (Acosta, Coronado, Ferrándiz, \& León, 2011; Chen, 2012; Didegah \& Thelwall, 2013; Lee, 2010; Lee, Lee, Song, \& Lee, 2007; Messinis, 2011; Upham, Rosenkopf, \& Ungar, 2010; Yoshikane, 2013).

ZINB regression assumes there are two different processes that influence the zero outcome: a general process that influences all cited and non-cited publication and also another process that influences only publications that receive zero citation (Desmarais \& Harden, 2013). Following this logic, ZINB regression has two parts. The main part looks at the influence of variables on citation counts which might include some 0 citations by using a negative binomial procedure. The inflate part includes a logit regression to predict the factors influencing having always 0 citation. We used the ZINB regression inflate part to investigate the factors related to receiving the first citation and the ZINB regression main part to explore the factors related to receiving citation in general.

We also conducted an additional logistic regression analysis for the top percentile citations to investigate the relationship between funding and highly-cited publications. This is conducted by using a derived dichotomous variable taking 1 if the number of citations are in the top percentile of the country subset it belongs to.

Both parts of the ZINB model use the number of citation counts as dependent variable. Receiving funding from national international, EU and non-governmental and corporate sources (f_national, f_international, $f_{-} e u, f \_$private) along with quadratic and linear forms of funding intensity and variety ( $f$ _intensity, $f_{-}$variety) are the main independent variables. We also used six broad subject categories (s_biologyandmedicine, s_environmentalst, s_physicalst, s_psychologyandsocialsciences, s_computersciandengineering, s_socialsciences), continental locations of international co-authors (c_europe, c_northamerica, c_asia, c_oceania, c_africa, c_southamerica), number of authors (n_authors) and years lapsed since publication (o_yearslapsed) as control variables.

\section{Results}

A descriptive analysis of the data indicates that there are differences among the six countries. The mean citation count is lowest in Norway (3.22) and highest in Switzerland (4.58) while this measure ranges between these values for the other four countries. The standard deviation of citation counts is around 7 for Norway, between 11 and 12 for Belgium, Denmark, Switzerland and Sweden and 15 for Netherlands. A standard deviation higher than the mean is expected given citation distribution patterns, with many zero cites coupled with a rightward tail of very highly cited papers. Just under four-fifths of papers published between 2009 and 2011 had attract zero citations by 2012 across all countries, except Switzerland where the proportion of zero-cited papers 

is slightly lower. Funding intensity (f_intensity) is comparable (around 0.30) for Denmark, Belgium, Switzerland and the Netherlands, while it is significantly higher in Norway and Sweden (around 0.70). Funding variety (f_variety) is relatively stable across six countries, ranging between 0.50 and 0.60. Finally, disciplinary distribution and collaboration with other countries follow broadly similar patterns in all six countries (Table 2).

Table 2: Descriptive Statistics

\begin{tabular}{|c|c|c|c|c|c|c|}
\hline & Denmark & Belgium & Switzerland & Netherlands & Norway & Sweden \\
\hline & Mean (Standar & Deviation) & & & & \\
\hline \multirow{6}{*}{ timescited } & $3.96(11.02)$ & $3.75(11.35)$ & $4.58(12.33)$ & $3.94(15.39)$ & $3.22(7.64)$ & $\begin{array}{l}3.61 \\
(11.45)\end{array}$ \\
\hline & \multicolumn{6}{|l|}{ Range (Median) } \\
\hline & $380(1)$ & $832(1)$ & $832(1)$ & $2882(1)$ & $336(1)$ & $832(1)$ \\
\hline & \multicolumn{6}{|c|}{ Percentage of 0 values } \\
\hline & $37.21 \%$ & $38.01 \%$ & $34.53 \%$ & $37.17 \%$ & $38.13 \%$ & $38.57 \%$ \\
\hline & \multicolumn{6}{|c|}{ Mean (Standard Deviation) } \\
\hline f_intensity & $0.37(0.54)$ & $0.31(0.46)$ & $0.31(0.44)$ & $0.35(0.82)$ & $0.78(1.92)$ & $0.69(1.45)$ \\
\hline f_variety & $0.57(0.47)$ & $0.57(0.47)$ & $0.59(0.47)$ & $0.47(0.48)$ & $0.49(0.46)$ & $0.60(0.47)$ \\
\hline f_national & $0.33(0.47)$ & $0.39(0.49)$ & $0.31(0.46)$ & $0.24(0.43)$ & $0.38(0.49)$ & $0.41(0.49)$ \\
\hline f_international & $0.26(0.44)$ & $0.24(0.43)$ & $0.29(0.45)$ & $0.21(0.41)$ & $0.23(0.42)$ & $0.25(0.44)$ \\
\hline f_eu & $0.19(0.40)$ & $0.13(0.34)$ & $0.12(0.32)$ & $0.10(0.30)$ & $0.09(0.28)$ & $0.11(0.31)$ \\
\hline f_private & $0.11(0.32)$ & $0.06(0.23)$ & $0.10(0.30)$ & $0.06(0.25)$ & $0.06(0.23)$ & $0.18(0.38)$ \\
\hline s_biologyandmedicine & $0.53(0.50)$ & $0.51(0.50)$ & $0.50(0.50)$ & $0.50(0.50)$ & $0.46(0.50)$ & $0.49(0.50)$ \\
\hline s_environmentalst & $0.14(0.35)$ & $0.12(0.33)$ & $0.13(0.34)$ & $0.11(0.31)$ & $0.25(0.43)$ & $0.13(0.34)$ \\
\hline s_physicalst & $0.22(0.41)$ & $0.29(0.45)$ & $0.31(0.46)$ & $0.19(0.40)$ & $0.18(0.38)$ & $0.24(0.43)$ \\
\hline s_psychologyandsocialsciences & $0.12(0.32)$ & $0.11(0.31)$ & $0.10(0.30)$ & $0.18(0.38)$ & $0.16(0.37)$ & $0.14(0.35)$ \\
\hline s_computersciandengineering & $0.08(0.27)$ & $0.13(0.34)$ & $0.09(0.29)$ & $0.09(0.29)$ & $0.10(0.31)$ & $0.09(0.28)$ \\
\hline s_socialsciences & $0.18(0.39)$ & $0.13(0.33)$ & $0.12(0.32)$ & $0.26(0.44)$ & $0.19(0.39)$ & $0.20(0.40)$ \\
\hline c_europe & $0.44(0.50)$ & $0.50(0.50)$ & $0.52(0.50)$ & $0.40(0.49)$ & $0.43(0.50)$ & $0.42(0.49)$ \\
\hline c_northamerica & $0.19(0.40)$ & $0.18(0.38)$ & $0.23(0.42)$ & $0.18(0.39)$ & $0.18(0.39)$ & $0.18(0.38)$ \\
\hline c_asia & $0.09(0.29)$ & $0.10(0.30)$ & $0.11(0.31)$ & $0.09(0.29)$ & $0.09(0.29)$ & $0.11(0.32)$ \\
\hline c_oceania & $0.05(0.21)$ & $0.03(0.18)$ & $0.04(0.20)$ & $0.03(0.18)$ & $0.04(0.19)$ & $0.04(0.19)$ \\
\hline c_africa & $0.02(0.15)$ & $0.04(0.20)$ & $0.03(0.16)$ & $0.02(0.15)$ & $0.03(0.18)$ & $0.02(0.15)$ \\
\hline c_southamerica & $0.02(0.15)$ & $0.03(0.17)$ & $0.03(0.16)$ & $0.02(0.14)$ & $0.02(0.13)$ & $0.02(0.14)$ \\
\hline n_authors & 12.67 (130.68) & $12.76(106.02)$ & $16.68(139.44)$ & $10.83(87.10)$ & $15.76(146.93)$ & $\begin{array}{l}11.54 \\
(103.91)\end{array}$ \\
\hline \multirow[t]{2}{*}{ o_yearslapsed } & $1.93(0.82)$ & $1.95(0.82)$ & $1.94(0.82)$ & $1.96(0.82)$ & $1.98(0.81)$ & $1.97(0.82)$ \\
\hline & \multicolumn{6}{|l|}{ Count } \\
\hline $\mathrm{N}$ & 29,356 & 38,108 & 49,961 & 75,174 & 24,280 & 49,721 \\
\hline
\end{tabular}

Around $44 \%$ of the publications in our data set acknowledge funding sources except for the Netherlands where this ratio is around $56 \%$. This is somewhat lower than the percentage of all papers in SCI reporting funding acknowledgements (see section 2.4 of this paper), suggesting that researchers in the six small European countries examined are more reliant on core funding than researchers in large science performing countries (such as China, the US, Germany, Japan and the UK). Across the six countries, national public funding ranges between $24 \%$ and $41 \%$, international public funding between $29 \%$ and $21 \%$, EU funding between $9 \%$ and $19 \%$ and nongovernmental and corporate funding between $6 \%$ and $18 \%$ (Table 2 ).

ZINB regression results show that all four categories of funding are related to increased levels of citation impact in all six country sub-datasets (Table 3 and Table 4). The main part of the ZINB 
regression, which shows the impact of funding on citation counts, has positive and significant relationships for all funding categories and thus it corroborates that funding is positively related with citation count. However, incidence rate ratios reveal that the association of funding sources to citation impact differs greatly between countries and different sources. For instance, the relative contribution of all funding sources is higher in Switzerland than for the other countries. Similarly, in general the association of non-governmental and corporate funding with citation is higher than other funding sources.

Table 3: Summary of the Regression Results

\begin{tabular}{|c|c|c|c|c|c|c|}
\hline & Belgium & Denmark & Netherlands & Norway & Sweden & Switzerland \\
\hline & \multicolumn{6}{|c|}{ Impact on Citation Count (ZINB Main Part, Incidence Rate Ratios) } \\
\hline National Public Funding & $12.7 \%$ & $14.4 \%$ & $20.1 \%$ & $14.9 \%$ & $13.5 \%$ & $28.6 \%$ \\
\hline $\begin{array}{ll}\text { International } & \text { Public } \\
\text { Funding } & \\
\end{array}$ & $17.9 \%$ & $17.4 \%$ & $18.5 \%$ & $22.1 \%$ & $22.6 \%$ & $27.8 \%$ \\
\hline EU Funding & $13.8 \%$ & $21.8 \%$ & $14.4 \%$ & $15.8 \%$ & $20.6 \%$ & $29.0 \%$ \\
\hline $\begin{array}{l}\text { Non-Governmental } \\
\text { Corporate Funding }\end{array}$ & $49.3 \%$ & $30.1 \%$ & $31.6 \%$ & $25.9 \%$ & $29.1 \%$ & $31.0 \%$ \\
\hline Funding Intensity & Negative & Negative & Negative & Negative & Negative & Negative \\
\hline Funding Variety & Positive & Positive & Positive & Positive & Positive & Positive \\
\hline & \multicolumn{6}{|c|}{$\begin{array}{l}\text { Impact on Being in Always Zero Citation Group } \\
\text { (ZINB Inflate Part, Incidence Rate Ratios) }\end{array}$} \\
\hline National Public Funding & $-25.6 \%$ & NS & $-19.9 \%$ & NS & NS & NS \\
\hline $\begin{array}{l}\text { International } \\
\text { Funding }\end{array}$ & NS & NS & NS & NS & NS & NS \\
\hline EU Funding & NS & $-27.5 \%$ & NS & NS & NS & NS \\
\hline $\begin{array}{ll}\text { Non-Governmental } & \text { and } \\
\text { Corporate Funding } & \\
\end{array}$ & NS & NS & NS & NS & NS & $-32.9 \%$ \\
\hline Funding Intensity & Negative & NS & NS & NS & Negative & NS \\
\hline Funding Variety & NS & NS & NS & NS & $\mathrm{NS}$ & NS \\
\hline & \multicolumn{6}{|c|}{ Impact on Being Top Percentile Cited Group (Logistic, Odds Ratios) } \\
\hline National Public Funding & $38.2 \%$ & $19.1 \%$ & $38.0 \%$ & $34.0 \%$ & $20.2 \%$ & $35.5 \%$ \\
\hline $\begin{array}{l}\text { International } \quad \text { Public } \\
\text { Funding }\end{array}$ & $22.1 \%$ & $23.6 \%$ & $20.1 \%$ & $30.1 \%$ & $28.8 \%$ & $38.3 \%$ \\
\hline EU Funding & $12.1 \%$ & $35.5 \%$ & $16.0 \%$ & $25.6 \%$ & $24.6 \%$ & $31.4 \%$ \\
\hline $\begin{array}{l}\text { Non-Governmental and } \\
\text { Corporate Funding }\end{array}$ & $45.0 \%$ & $24.4 \%$ & $18.9 \%$ & $22.2 \%$ & $27.3 \%$ & $38.9 \%$ \\
\hline Funding Intensity & $\mathrm{NS}$ & Negative & $\mathrm{NS}$ & NS & $\mathrm{NS}$ & $\mathrm{NS}$ \\
\hline Funding Variety & Positive & Positive & Positive & NS & Positive & Positive \\
\hline
\end{tabular}

Only significant results for $p<0.05$ are shown. NS denotes not significant.

We did not find that funding is significantly related with attracting the first citation. The ZINB regression inflate part measures the probability of being in always zero citation group. There are only a limited number of significant negative relationships between funding categories and being in the always zero citation group. This indicates that while funding is associated with higher citations, for papers that receive citations, funding is not positively related with receiving any citation at all. In other words, there are publications that will not receive any cites even if they are funded. 
Logistic regression looking at the relationship between funding and being in top percentile citation group shows positive and significant results (Table 3 for summary and Table 5 for details). The variety between countries and different funding sources in receiving top percentile citations follows roughly the same pattern we found in citation counts as discussed above. All in all, these results show that funding is positively related with increased citation counts and being among the top cited publications but it is not often associated with receiving the first citation. Therefore, we partially accept $\mathrm{H} 1$ that funding is positively associated with citation impact.

Both the main part of the ZINB regression and logistic regression predicting a paper is in the top percentile funded publications indicate that the contribution of some funding categories is higher than others. Receiving non-governmental and corporate funding is always the highest contributor to citation counts and national public funding is the lowest contributor. The gap between these two funding sources is wide in most of the countries. For instance, in Belgium, where receiving the former type of funding increases citations by $49.3 \%$ and latter only by $12.7 \%$ (Table 3 ), there is also a significant inverse correlation between the relative frequency of funding (share of papers that received a funding type) and the relative impact of funding $(r=-0.5132, p=0.0103)$. In other words, the higher the relative frequency of a funding, the less its relative impact on citation counts. For instance, National funders of all five countries are consistently more frequent acknowledged than corporate and non-governmental funders and the citations for the publications funded for the latter are higher than the latter. There are some counter-examples for this trend such as the fact that the Swiss publications are cited higher than most other publications from other countries; however, this trend generally holds and the fitted line for this relationship is downward sloping and curvilinear (Figure 1).

While the inverse relationship between the relative frequency of and the relative impact of funding holds for citation counts, there is no statistically significant link between relative frequency of funding and first citation or top percentile citation $(r=0.1566, p=0.4648$, 
Figure 2). Therefore, we accept H2 that there is indeed a hierarchy of funding sources in terms of impact and this hierarchy is inversely related to their relative frequencies.

Figure 1: Relationship between Contribution to the Increased Citation Impact and Relative Frequency of Funding

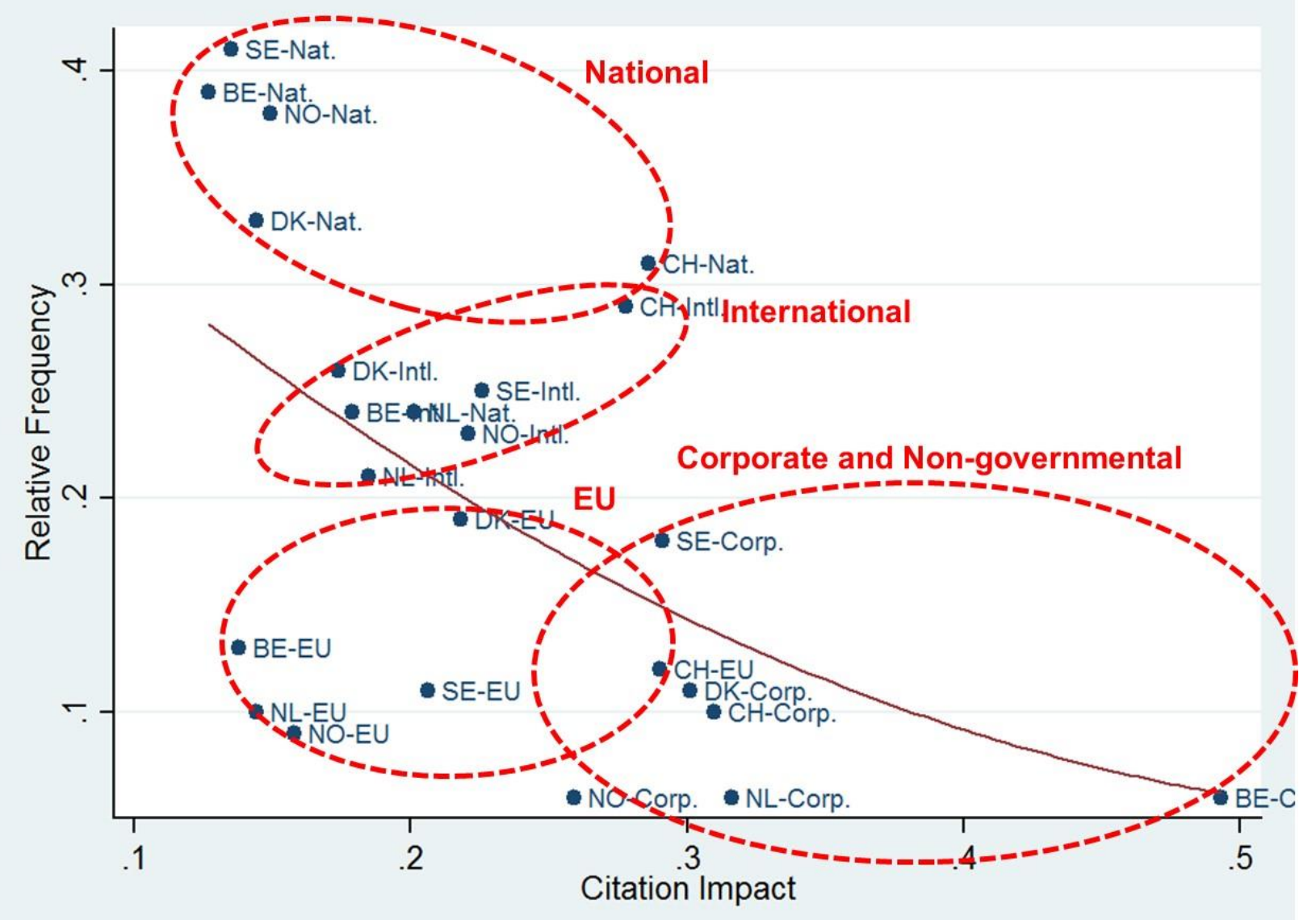


Figure 2: Relationship between Contribution to the Increased Citation Impact for High Levels of Citation and Relative

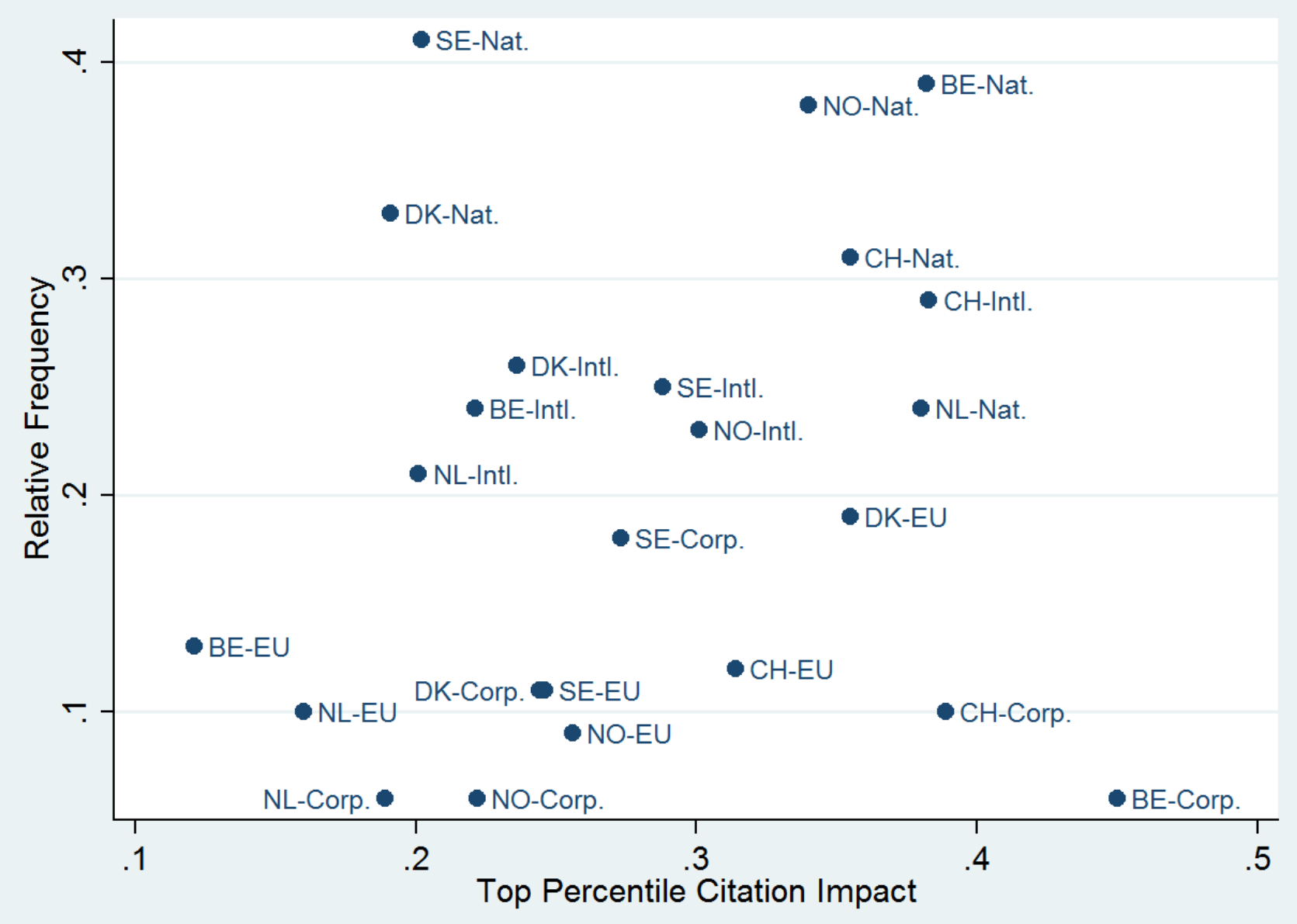

Funding intensity (the number of funders acknowledged relative to the number of authors) is always significantly associated with citation counts. ${ }^{8}$ However, the relationship is negative for all countries. Except for a small number of exceptions, funding intensity is not significantly linked to the first and top percentile citations. This implies that increased number of funders relative to the number of authors for a paper is not always associated with increased citation impact. However, funding variety (the proportion of unique funding organizations acknowledged) for publication increases citation count impact (Table 3 and Table 4). It is also positively linked with top percentile impact, while it does not have a significant relationship with the first citation. Therefore, we partially accept H3 that intensity and variety in funding sources are associated with increased citation impact.

\section{Discussion and Conclusions}

Our investigation of the relationships between funding and citation impact indicates that while funding is not related to receiving the first citation, it is highly linked to citation counts and top

8 We also investigated quadratic forms of funding intensity and variety but they did not decrease AIC dramatically and in some cases introduced non-converging results. 
percentile citations. In principle, the processes of review undertaken as part of external sponsorship should help to ensure higher quality research. In practice, there are a number of caveats that need to be kept in mind. External peer review of research can be conservative or driven by factors other than maximizing research impact; researchers do not always deliver on the promises made in funded proposals; the processes of journal peer review for high impact journals may favor certain kinds of research (and researchers) above others; and, while researchers may publish multiple papers from a project, these various papers will likely focus on different aspects and not all will attract citation. Core funded work (without any acknowledgement of specific research sponsors or external awards) is just as likely as funded research to receive zero citations. However, in terms of highly-cited research, there is an association with research funding. Potentially, the added resources made available through external sponsorship, coupled with the processes of explicitly structuring research (most external funders expect to see research objectives, plans, strategies, and dissemination approaches), combine to give funded research an edge over non-funded research in producing publications with qualities able to garner high citations.

A second finding is that there is a hierarchy of citation impacts associated with different funding sources. There are variations by country, for example, national funding in the Netherlands has a higher incidence of citation impact than EU funding, while for Switzerland there is little difference between the relative citation impacts associated with national and EU funding. However, overall, for our set of six small European countries, we find that non-governmental sources are more likely to be associated with higher citation impact papers than international or European Union funding, with national funding having a lower incidence of impact. We further show that there is an inverse relationship between the relative frequency of a funding source and its citation impact. A probable cause for this might be that an increased frequency in awarding funding decreases the capability of the source in identifying research which has high research impact potential. On the contrary, less frequent funding sources such as corporate and non-governmental funders might be more selective in funding research with higher impact potential. This might also be related to the funding priorities of the funders, or reputational competition for smaller funders. Similarly, while high frequency funders might cover a relatively larger ground of research at the expense of decreased impact, low frequency funders are often considerably more focused. Moreover, national public funders, the most frequent funder, often do not target citations only but pursue other strategic objectives and responsive behavior in research funding. This is also the case for European research programs, especially those which seek broad participation from multiple countries.

Our third finding is related to funding intensity and variety. We find that funding intensity is negatively related to citation impact and not related to the first and top percentile impact. On the other hand, funding variety increases the citation counts and top percentile citation impact. This 
might be explained by the enriched experience and resource contributions brought in by additional funders. As the quadratic forms failed to improve our model, we have established that there is no significant diminishing returns of funding variety due to increased reporting requirements imposed by different funders.

While our results are significant, we acknowledge that there are a number of limitations of this study. While we do control for such factors as the number of authors, international co-authorship, and subject categories, it may be that there are further uncontrolled factors influencing our results. The data we use may underplay the role of core funding that researchers receive but do not usually acknowledge. Researchers are more likely to acknowledge project based funding, often due to the requirements of their funders. We recognize that there is a significant amount of funding from the funders we investigate in the study to researchers through core funding of the researchers' institutions. A second limitation is related to the funding amounts. As funding amounts are not recorded in the WoS, we could not weight the funding. This might introduce a degree of bias against corporate and non-governmental funders if funding amounts from these sources are systematically different than from other funders. Finally, there is a risk of inverse causation between funding and citation impact.

In spite of these limitations, our paper contributes into an important gap by shedding more light in understanding the impact of research funding on scientific outputs. The results prompt further questions, including how should research funding bodies design their strategies and how much can design influence knowledge generation and research (including citation) impact? How much can funding bodies affect topic focus and the international reach of their funding? And, to what extent can funding bodies influence research actors through the design of their programs and the incentives they offer? Such questions are appropriate and timely topics for exploration in additional research and for management and policy deliberation.

Acknowledgements: Assistance in data cleaning for this research was provided by Evgeny Klochikin. An earlier version of the paper was presented at the 5th Biennial Atlanta Conference on Science and Innovation Policy, Georgia Institute of Technology, Atlanta, September 28, 2013. We gratefully acknowledge comments received from participants at this conference and from the anonymous journal reviewers. 
Table 4: Results of the ZINB Citation Impact Model (Incidence Rate Ratios)

\begin{tabular}{|c|c|c|c|c|c|c|}
\hline & $\begin{array}{l}(1) \\
\text { be1 }\end{array}$ & $\begin{array}{l}\text { (2) } \\
\text { no1 }\end{array}$ & $\begin{array}{l}\text { (3) } \\
\text { ch1 }\end{array}$ & $\begin{array}{l}\text { (4) } \\
\mathrm{dk} 1\end{array}$ & $\begin{array}{l}\text { (5) } \\
\text { nl1 }\end{array}$ & $\begin{array}{l}\text { (6) } \\
\text { se1 }\end{array}$ \\
\hline \multicolumn{7}{|l|}{ timescited } \\
\hline \multirow[t]{2}{*}{ f_national } & $1.127^{* * * *}$ & $1.149^{* * *}$ & $1.286^{* * *}$ & $1.144^{* * *}$ & $1.201^{* * *}$ & $1.135^{* * *}$ \\
\hline & $(6.15)$ & $(6.20)$ & $(15.75)$ & $(6.19)$ & $(12.62)$ & $(7.78)$ \\
\hline \multirow[t]{2}{*}{ f_international } & $1.179^{* * *}$ & $1.221^{* * *}$ & $1.278^{* * *}$ & $1.174^{* * * *}$ & $1.185^{* * *}$ & $1.226^{* * *}$ \\
\hline & $(8.39)$ & $(8.37)$ & $(14.85)$ & (7.33) & (11.17) & (12.36) \\
\hline f_eu & $1.138^{* * *}$ & $1.158^{* * *}$ & $1.290^{* * *}$ & $1.217^{* * *}$ & $1.144^{* * *}$ & $1.206^{* * *}$ \\
\hline & $(5.81)$ & $(4.63)$ & $(12.79)$ & $(8.39)$ & $(7.63)$ & (8.94) \\
\hline f_private & $1.493^{* * * *}$ & $1.259^{* * *}$ & $1.310^{* * * *}$ & $1.301^{* * * *}$ & $1.316^{* * *}$ & $1.291^{* * * *}$ \\
\hline & (12.94) & $(6.12)$ & $(12.32)$ & $(9.84)$ & $(12.79)$ & (14.73) \\
\hline f_intensity & $0.936^{* * *}$ & $0.973^{* * *}$ & $0.928^{* * * *}$ & $0.900^{* * * *}$ & $0.973^{* * *}$ & $0.966^{* * * *}$ \\
\hline & $(-3.52)$ & $(-5.14)$ & $(-4.31)$ & $(-5.76)$ & $(-3.67)$ & $(-7.03)$ \\
\hline f_variety & $1.212^{* * * *}$ & $1.068^{* *}$ & $1.140^{* * *}$ & $1.169^{* * *}$ & $1.234^{* * *}$ & $1.142^{* * * *}$ \\
\hline & $(8.94)$ & $(2.64)$ & $(7.21)$ & $(6.49)$ & (13.85) & (7.12) \\
\hline n_authors & $0.999^{* * *}$ & $0.999^{* * *}$ & $0.999^{* * *}$ & $0.999^{* * *}$ & $0.999^{* * *}$ & $0.999^{* * *}$ \\
\hline & $(-14.17)$ & $(-10.20)$ & $(-16.94)$ & $(-11.37)$ & $(-11.97)$ & $(-13.15)$ \\
\hline o_yearslapsed & $2.558^{* * * *}$ & $2.565^{* * *}$ & $2.632^{* * * *}$ & $2.609^{* * * *}$ & $2.645^{* * *}$ & $2.663^{* * *}$ \\
\hline & (83.35) & $(66.86)$ & $(102.08)$ & (74.28) & (120.64) & (96.52) \\
\hline s_biologyandmedicine & $1.253^{* * * *}$ & $1.283^{* * *}$ & $1.165^{* * *}$ & $1.307^{* * *}$ & $1.606^{* * *}$ & $1.406^{* * * *}$ \\
\hline & $(9.61)$ & $(9.16)$ & $(7.00)$ & $(9.63)$ & $(28.45)$ & (16.91) \\
\hline s_environmentalst & $0.806^{* * *}$ & $0.873^{* * *}$ & $0.812^{* * *}$ & $0.839^{* * *}$ & 0.989 & $0.951^{*}$ \\
\hline & $(-7.93)$ & $(-4.76)$ & $(-8.56)$ & $(-5.97)$ & $(-0.53)$ & $(-2.26)$ \\
\hline s_physicalst & $1.051^{*}$ & 0.996 & $1.072^{* *}$ & $1.362^{* * *}$ & $1.395^{* * *}$ & $1.209^{* * * *}$ \\
\hline & $(2.03)$ & $(-0.14)$ & (3.04) & $(10.24)$ & (18.06) & (8.76) \\
\hline s_psychologyandsocialsciences & 0.892 & $0.832^{* *}$ & $0.840^{* *}$ & $1.396^{* * *}$ & $1.291^{* * *}$ & $1.189^{* * *}$ \\
\hline & $(-1.91)$ & $(-2.94)$ & $(-3.07)$ & (7.43) & (10.46) & (4.91) \\
\hline s_computersciandengineering & $0.561^{* * *}$ & $0.537^{* * *}$ & $0.469^{* * *}$ & $0.572^{* * *}$ & $0.600^{* * * *}$ & $0.570^{* * *}$ \\
\hline & $(-20.83)$ & $(-16.86)$ & $(-27.96)$ & $(-15.10)$ & $(-23.72)$ & $(-20.46)$ \\
\hline s_socialsciences & 0.940 & 1.023 & $0.883^{*}$ & $0.557^{* * *}$ & $0.704^{* * *}$ & $0.698^{* * * *}$ \\
\hline - & $(-1.11)$ & $(0.39)$ & $(-2.35)$ & $(-13.56)$ & $(-13.95)$ & $(-10.37)$ \\
\hline n_countries & $1.115^{* * *}$ & $1.105^{* * *}$ & $1.111^{* * *}$ & $1.106^{* * *}$ & $1.103^{* * *}$ & $1.116^{* * *}$ \\
\hline & (19.94) & $(16.56)$ & $(21.33)$ & $(16.79)$ & $(22.73)$ & (22.47) \\
\hline c_europe & $1.148^{* * * *}$ & $1.214^{* * *}$ & 1.025 & $1.108^{* * * *}$ & $1.143^{* * *}$ & $1.190^{* * * *}$ \\
\hline & $(7.50)$ & $(8.63)$ & $(1.55)$ & $(4.78)$ & $(9.74)$ & (10.56) \\
\hline c_northamerica & $1.435^{* * *}$ & $1.442^{* * *}$ & $1.355^{* * *}$ & $1.453^{* * *}$ & $1.421^{* * *}$ & $1.577^{* * * *}$ \\
\hline & $(17.31)$ & $(14.68)$ & $(18.00)$ & $(16.19)$ & $(23.38)$ & (24.88) \\
\hline c_asia & 0.959 & 1.015 & $0.948^{*}$ & 0.979 & $0.873^{* * *}$ & 0.959 \\
\hline & $(-1.57)$ & $(0.45)$ & $(-2.41)$ & $(-0.69)$ & $(-6.83)$ & $(-1.91)$ \\
\hline c_oceania & $1.101^{*}$ & $1.221^{* * *}$ & $1.198^{* * *}$ & $1.138^{* * *}$ & $1.140^{* * * *}$ & $1.147^{* * * *}$ \\
\hline & $(2.36)$ & $(4.30)$ & $(5.57)$ & $(3.20)$ & $(4.64)$ & $(4.09)$ \\
\hline c_africa & $0.747^{* * *}$ & $0.781^{* * *}$ & $0.914^{*}$ & $0.815^{* * *}$ & $0.711^{* * *}$ & $0.788^{* * * *}$ \\
\hline & $(-7.62)$ & $(-4.73)$ & $(-2.23)$ & $(-3.63)$ & $(-9.44)$ & $(-5.62)$ \\
\hline c_southamerica & $0.914^{*}$ & 0.920 & $0.856^{* * * *}$ & $0.884^{*}$ & $0.838^{* * * *}$ & $0.878^{* *}$ \\
\hline & $(-2.07)$ & $(-1.18)$ & $(-3.77)$ & $(-2.17)$ & $(-4.77)$ & $(-2.94)$ \\
\hline _cons & $0.229^{* * * *}$ & $0.210^{* * * *}$ & $0.280^{* * * *}$ & $0.230^{* * * *}$ & $0.192^{* * *}$ & $0.166^{* * * *}$ \\
\hline & $(-36.92)$ & $(-32.33)$ & $(-36.44)$ & $(-32.40)$ & $(-59.32)$ & $(-51.44)$ \\
\hline inflate & & & & & & \\
\hline f_national & $0.774^{* *}$ & 0.945 & 0.961 & 1.079 & $0.820^{* *}$ & 1.103 \\
\hline & $(-2.77)$ & $(-0.49)$ & $(-0.55)$ & $(0.79)$ & $(-2.90)$ & $(1.22)$ \\
\hline f_international & 1.135 & 0.923 & $0.689^{* * *}$ & 0.989 & 0.960 & 0.976 \\
\hline & $(1.36)$ & $(-0.65)$ & $(-5.08)$ & $(-0.11)$ & $(-0.57)$ & $(-0.28)$ \\
\hline f_eu & 0.999 & 0.894 & 0.924 & $0.760^{* * *}$ & 0.923 & 0.968 \\
\hline & $(-0.01)$ & $(-0.72)$ & $(-0.94)$ & $(-2.59)$ & $(-0.99)$ & $(-0.34)$ \\
\hline f_private & 0.934 & 0.824 & $0.720^{* * *}$ & 0.829 & 0.984 & 1.017 \\
\hline & $(-0.50)$ & $(-1.02)$ & $(-3.53)$ & $(-1.55)$ & $(-0.17)$ & $(0.20)$ \\
\hline s_biologyandmedicine & 1.165 & $0.649^{*}$ & 0.823 & $1.308^{*}$ & $1.304^{* *}$ & 0.901 \\
\hline & $(1.33)$ & $(-2.35)$ & $(-1.71)$ & $(2.02)$ & (3.09) & $(-0.89)$ \\
\hline s_environmentalst & 0.826 & $0.580^{* *}$ & $0.586^{* * *}$ & $0.719^{*}$ & 0.829 & $0.726^{*}$ \\
\hline & $(-1.37)$ & $(-2.77)$ & $(-3.98)$ & $(-2.26)$ & $(-1.81)$ & $(-2.47)$ \\
\hline s_physicalst & 0.931 & $0.474^{* * *}$ & $0.651^{* * *}$ & 0.817 & 0.995 & $0.743^{*}$ \\
\hline & $(-0.61)$ & $(-3.41)$ & $(-3.55)$ & $(-1.46)$ & $(-0.05)$ & $(-2.41)$ \\
\hline s_psychologyandsocialsciences & 1.238 & 0.811 & 0.682 & 0.844 & 1.000 & 0.856 \\
\hline & $(0.62)$ & $(-0.54)$ & $(-1.29)$ & $(-0.67)$ & $(0.00)$ & $(-0.74)$ \\
\hline s_computersciandengineering & 1.187 & 0.712 & 1.293 & 0.947 & $1.286^{*}$ & 1.012 \\
\hline & $(1.23)$ & $(-1.43)$ & $(1.87)$ & $(-0.28)$ & $(2.14)$ & $(0.07)$ \\
\hline s_socialsciences & 0.656 & 0.898 & 1.317 & 1.001 & 0.809 & 1.057 \\
\hline & $(-1.31)$ & $(-0.30)$ & $(0.99)$ & $(0.00)$ & $(-1.41)$ & $(0.27)$ \\
\hline n_countries & 1.029 & $0.947^{*}$ & 1.000 & 1.041 & $1.064^{*}$ & 1.030 \\
\hline & $(0.82)$ & $(-2.29)$ & $(0.00)$ & $(1.27)$ & (2.39) & $(0.67)$ \\
\hline c_europe & $0.795^{*}$ & 1.023 & 0.912 & 0.959 & 1.014 & 1.015 \\
\hline & $(-2.50)$ & $(0.20)$ & $(-1.32)$ & $(-0.43)$ & $(0.20)$ & $(0.19)$ \\
\hline c_northamerica & 1.062 & 0.977 & 0.946 & 0.847 & 0.957 & 1.052 \\
\hline & $(0.63)$ & $(-0.20)$ & $(-0.74)$ & $(-1.63)$ & $(-0.61)$ & $(0.62)$ \\
\hline c_asia & $1.284^{*}$ & $1.718^{* * * *}$ & $1.262^{*}$ & $1.367^{*}$ & $1.201^{*}$ & $1.258^{*}$ \\
\hline & $(2.11)$ & $(3.52)$ & (2.53) & $(2.41)$ & (1.99) & $(2.27)$ \\
\hline c_oceania & $0.608^{*}$ & 1.114 & 1.144 & 0.842 & 1.005 & 0.935 \\
\hline & $(-2.22)$ & $(0.51)$ & (1.04) & $(-0.91)$ & $(0.03)$ & $(-0.38)$ \\
\hline c_africa & $1.431^{*}$ & 1.208 & $0.678^{*}$ & 0.715 & 0.913 & $1.466^{*}$ \\
\hline & $(2.07)$ & $(0.74)$ & $(-1.97)$ & $(-1.04)$ & $(-0.47)$ & (1.98) \\
\hline c_southamerica & 1.071 & 0.888 & $0.641^{*}$ & 0.930 & 0.716 & 0.780 \\
\hline & $(0.33)$ & $(-0.35)$ & $(-2.03)$ & $(-0.25)$ & $(-1.51)$ & $(-0.98)$ \\
\hline f_intensity & $0.651^{* * * *}$ & 0.932 & 0.919 & 0.968 & 0.943 & $0.862^{* *}$ \\
\hline & $(-3.40)$ & $(-1.46)$ & $(-0.95)$ & $(-0.34)$ & $(-1.32)$ & $(-2.82)$ \\
\hline f_variety & 1.182 & 0.932 & 1.033 & 0.857 & 0.949 & 0.864 \\
\hline & (1.64) & $(-0.53)$ & (0.39) & $(-1.36)$ & $(-0.70)$ & $(-1.50)$ \\
\hline n_authors & $0.912^{* * * *}$ & 1.000 & 1.000 & $0.952^{* * *}$ & $0.922^{* * *}$ & 0.963 \\
\hline
\end{tabular}


The Impact of Research Funding on Scientific Outputs

\begin{tabular}{|c|c|c|c|c|c|c|}
\hline \multirow{3}{*}{ o_yearslapsed } & $(-7.25)$ & $(1.41)$ & $(0.44)$ & $(-3.36)$ & $(-8.04)$ & $(-1.34)$ \\
\hline & $9.87 \mathrm{e}-09$ & $1.04 \mathrm{e}-08$ & $2.81 \mathrm{e}-09$ & $5.09 \mathrm{e}-09$ & $1.36 \mathrm{e}-09$ & $5.73 \mathrm{e}-09$ \\
\hline & $(-0.05)$ & $(-0.04)$ & $(-0.04)$ & $(-0.04)$ & $(-0.03)$ & $(-0.05)$ \\
\hline _cons & $\begin{array}{l}143327000.2 \\
(0.05)\end{array}$ & $\begin{array}{l}132374216.4 \\
(0.04)\end{array}$ & $\begin{array}{l}356060762.2 \\
(0.04)\end{array}$ & $\begin{array}{l}183268028.4 \\
(0.04)\end{array}$ & $\begin{array}{l}656179258.7 \\
(0.03)\end{array}$ & $\begin{array}{l}178614251.6 \\
(0.05)\end{array}$ \\
\hline \multicolumn{7}{|l|}{ lnalpha } \\
\hline _cons & $\begin{array}{l}1.125^{* * *} \\
(10.42)\end{array}$ & $\begin{array}{l}1.006 \\
(0.42)\end{array}$ & $\begin{array}{l}1.153^{* * *} \\
(15.32)\end{array}$ & $\begin{array}{l}1.164^{* * *} \\
(12.13)\end{array}$ & $\begin{array}{l}1.151^{* * *} \\
(17.90)\end{array}$ & $\begin{array}{l}1.097^{* * * *} \\
(9.08)\end{array}$ \\
\hline$N$ & 38108 & 24280 & 49961 & 29356 & 75174 & 49721 \\
\hline AIC & 155036.1 & 94419.0 & 220570.6 & 121979.4 & 311229.2 & 197392.2 \\
\hline BIC & 155420.7 & 94783.4 & 220967.5 & 122352.3 & 311644.4 & 197788.8 \\
\hline
\end{tabular}

Exponentiated coefficients; $t$ statistics in parentheses

${ }^{*} p<0.05,{ }^{* *} p<0.01,{ }^{* * *} p<0.001$ 
Table 5: Results of the Logistics ZINB Citation Impact Model for Top Percentile Citations Model (Incidence Rate Ratios)

\begin{tabular}{|c|c|c|c|c|c|c|}
\hline & $\begin{array}{l}\text { (1) } \\
\text { be1_10p }\end{array}$ & $\begin{array}{l}\text { (2) } \\
\text { no1_10p }\end{array}$ & $\begin{array}{l}\text { (3) } \\
\text { ch1_10p }\end{array}$ & $\begin{array}{l}\text { (4) } \\
\text { dk1_10p }\end{array}$ & $\begin{array}{l}\text { (5) } \\
\text { nl1_10p }\end{array}$ & $\begin{array}{l}(6) \\
\text { se1_10p }\end{array}$ \\
\hline \multicolumn{7}{|l|}{ timescited } \\
\hline \multirow[t]{2}{*}{ f_national } & $1.382^{* * *}$ & $1.340^{* * * *}$ & $1.355^{\text {*** }}$ & $1.191^{* * * *}$ & $1.380^{* * * *}$ & $1.202^{* * *}$ \\
\hline & $(9.43)$ & $(7.33)$ & $(10.37)$ & $(4.67)$ & $(12.49)$ & $(6.47)$ \\
\hline \multirow[t]{2}{*}{ f_international } & $1.221^{* * *}$ & $1.301^{* * * *}$ & $1.383^{* * * *}$ & $1.236^{\text {**** }}$ & $1.201^{* * * *}$ & $1.288^{* * *}$ \\
\hline & $(5.59)$ & $(5.97)$ & $(10.59)$ & $(5.40)$ & $(6.63)$ & $(8.50)$ \\
\hline \multirow[t]{2}{*}{ f_eu } & $1.216^{* * * *}$ & $1.256^{\text {**** }}$ & $1.314^{* * * *}$ & $1.355^{\text {**** }}$ & $1.160^{\text {**** }}$ & $1.246^{* * * *}$ \\
\hline & $(4.88)$ & $(3.75)$ & $(7.30)$ & $(7.24)$ & $(4.60)$ & $(5.81)$ \\
\hline \multirow[t]{2}{*}{ f_private } & $1.450^{* * * *}$ & $1.222^{* *}$ & $1.389^{* * *}$ & $1.244^{* * * *}$ & $1.189^{* * * *}$ & $1.273^{\text {*** }}$ \\
\hline & $(6.28)$ & $(2.86)$ & $(7.94)$ & $(4.39)$ & $(4.36)$ & $(7.66)$ \\
\hline \multirow[t]{2}{*}{ f_intensity } & $0.922^{*}$ & 0.984 & $0.930^{*}$ & $0.915^{* *}$ & 0.987 & 0.995 \\
\hline & $(-2.36)$ & $(-1.86)$ & $(-2.32)$ & $(-2.70)$ & $(-1.13)$ & $(-0.58)$ \\
\hline \multirow[t]{2}{*}{ f_variety } & $1.387^{* * * *}$ & $1.115^{*}$ & $1.359^{* * * *}$ & $1.313^{* * * *}$ & $1.436^{\text {**** }}$ & $1.341^{* * * *}$ \\
\hline & $(8.54)$ & $(2.42)$ & $(9.52)$ & $(6.49)$ & $(13.50)$ & $(8.94)$ \\
\hline \multirow[t]{2}{*}{ n_authors } & $0.999^{\text {**** }}$ & $0.999^{\text {**** }}$ & $0.999^{* * * *}$ & $0.999^{* * * *}$ & $0.999^{* * * *}$ & $0.999^{* * *}$ \\
\hline & $(-6.37)$ & $(-5.88)$ & $(-6.67)$ & $(-6.81)$ & $(-6.05)$ & $(-6.48)$ \\
\hline \multirow[t]{2}{*}{ o_yearslapsed } & $4.878^{* * * *}$ & $4.694^{* * * *}$ & $5.095^{* * * *}$ & $5.069^{* * * *}$ & $4.781^{* * * *}$ & $4.812^{* * *}$ \\
\hline & $(87.95)$ & $(69.75)$ & $(99.08)$ & $(77.02)$ & (121.29) & $(100.25)$ \\
\hline \multirow[t]{2}{*}{ s_biologyandmedicine } & $1.286^{* * * *}$ & $1.501^{* * * *}$ & $1.238^{* * *}$ & $1.451^{* * * *}$ & $1.784^{* * *}$ & $1.685^{* * *}$ \\
\hline & $(6.47)$ & $(8.53)$ & $(5.81)$ & $(8.15)$ & $(20.99)$ & $(15.57)$ \\
\hline \multirow[t]{2}{*}{ s_environmentalst } & 0.998 & 1.091 & $1.146^{* *}$ & $1.189^{* * * *}$ & $1.285^{* * * *}$ & $1.312^{* * * *}$ \\
\hline & $(-0.03)$ & $(1.73)$ & $(3.23)$ & $(3.46)$ & $(7.50)$ & $(7.19)$ \\
\hline \multirow[t]{2}{*}{ s_physicalst } & $1.214^{* * * *}$ & $1.188^{* *}$ & $1.256^{* * *}$ & $1.685^{* * *}$ & $1.521^{* * * *}$ & $1.446^{* * *}$ \\
\hline & $(4.85)$ & $(3.23)$ & $(6.00)$ & $(10.55)$ & $(13.43)$ & $(10.33)$ \\
\hline \multirow[t]{2}{*}{ s_psychologyandsocialsciences } & 1.030 & 0.919 & 0.992 & $1.618^{* * * *}$ & $1.514^{* * *}$ & $1.293^{* * *}$ \\
\hline & $(0.31)$ & $(-0.79)$ & $(-0.08)$ & $(6.87)$ & $(10.90)$ & $(4.73)$ \\
\hline \multirow[t]{2}{*}{ s_computersciandengineering } & $0.524^{* * *}$ & $0.519^{* * *}$ & $0.428^{* * *}$ & $0.608^{* * *}$ & $0.587^{\text {*** }}$ & $0.573^{* * *}$ \\
\hline & $(-14.36)$ & $(-10.71)$ & $(-18.84)$ & $(-8.41)$ & $(-15.55)$ & $(-12.86)$ \\
\hline \multirow[t]{2}{*}{ s_socialsciences } & 1.037 & 1.076 & 0.940 & $0.585^{* * * *}$ & $0.784^{* * * *}$ & $0.772^{* * *}$ \\
\hline & $(0.41)$ & $(0.75)$ & $(-0.70)$ & $(-7.87)$ & $(-6.17)$ & $(-4.74)$ \\
\hline \multirow[t]{2}{*}{ n_countries } & $1.117^{* * * *}$ & $1.105^{* * *}$ & $1.079^{* * *}$ & $1.118^{* * * *}$ & $1.098^{* * * *}$ & $1.108^{* * *}$ \\
\hline & (10.29) & $(7.76)$ & $(7.87)$ & $(9.12)$ & $(10.75)$ & $(10.50)$ \\
\hline \multirow[t]{2}{*}{ c_europe } & $1.296^{* * * *}$ & $1.186^{* * * *}$ & $1.122^{* * *}$ & $1.127^{* *}$ & $1.154^{* * * *}$ & $1.149^{* * *}$ \\
\hline & $(8.04)$ & $(4.16)$ & $(4.06)$ & $(3.13)$ & $(5.85)$ & $(4.74)$ \\
\hline \multirow[t]{2}{*}{ c_northamerica } & $1.278^{* * * *}$ & $1.385^{\text {*** }}$ & $1.290^{* * * *}$ & $1.427^{* * * *}$ & $1.371^{\text {**** }}$ & $1.410^{* * * *}$ \\
\hline & $(6.28)$ & $(6.84)$ & $(8.10)$ & $(8.25)$ & $(11.27)$ & $(10.03)$ \\
\hline \multirow[t]{2}{*}{ c_asia } & $0.809^{* * *}$ & $0.755^{* * *}$ & $0.863^{* * *}$ & $0.818^{* * *}$ & $0.802^{\text {*** }}$ & $0.878^{* *}$ \\
\hline & $(-4.45)$ & $(-4.52)$ & $(-3.63)$ & $(-3.65)$ & $(-6.28)$ & $(-3.28)$ \\
\hline \multirow[t]{2}{*}{ c_oceania } & $1.314^{* * *}$ & 1.114 & 1.084 & 1.054 & 1.052 & 1.089 \\
\hline & $(3.36)$ & $(1.16)$ & $(1.30)$ & $(0.69)$ & $(0.96)$ & $(1.32)$ \\
\hline \multirow[t]{2}{*}{ c_africa } & $0.704^{* * *}$ & $0.815^{*}$ & 0.982 & $0.788^{*}$ & $0.737^{* * * *}$ & $0.711^{* * *}$ \\
\hline & $(-5.35)$ & $(-2.18)$ & $(-0.24)$ & $(-2.26)$ & $(-4.86)$ & $(-4.64)$ \\
\hline c_southamerica & $0.809^{* * *}$ & 0.965 & 0.919 & 0.852 & 0.904 & 1.043 \\
\hline & $(-2.62)$ & $(-0.26)$ & $(-1.10)$ & $(-1.46)$ & $(-1.38)$ & $(0.47)$ \\
\hline _cons & $0.0377^{* * *}$ & $0.0437^{* * * *}$ & $0.0477^{* * *}$ & $0.0371^{\text {*** }}$ & $0.0379^{* * *}$ & $0.0316^{\text {*** }}$ \\
\hline & $(-55.28)$ & $(-42.91)$ & $(-56.22)$ & $(-48.77)$ & $(-80.63)$ & $(-67.41)$ \\
\hline$N$ & 38108 & 24280 & 49961 & 29356 & 75174 & 49721 \\
\hline$A I C$ & 38832.3 & 25107.1 & 49381.0 & 29492.8 & 76438.5 & 50776.5 \\
\hline$B I C$ & 39020.3 & 25285.3 & 49575.1 & 29675.1 & 76641.5 & 50970.5 \\
\hline
\end{tabular}




\section{References}

Acosta, Manuel, Coronado, Daniel, Ferrándiz, Esther, \& León, M. Dolores. (2011). Factors affecting inter-regional academic scientific collaboration within Europe: the role of economic distance. Scientometrics, 87(1), 63-74. doi: 10.1007/s11192-010-0305-6

Arnold, E. (2012). Understanding long-term impacts of R\&D funding: The EU framework programme. Research Evaluation, 21(5), 332-343. doi: 10.1093/reseval/rvs025

Arnold, J. G., \& Fohrer, N. (2005). SWAT2000: current capabilities and research opportunities in applied watershed modelling. Hydrological Processes, 19(3), 563-572. doi: 10.1002/hyp.5611

Baldi, S. (1998). Normative versus social constructivist processes in the allocation of citations: A network-analytic model. American Sociological Review, 63(6), 829-846.

Bayona-Saez, C., \& Garcia-Marco, T. (2010). Assessing the effectiveness of the Eureka Program. Research Policy, 39(10), 1375-1386. doi: 10.1016/j.respol.2010.07.007

BIS (2011). Funding for EU Research and Innovation from 2014: A UK Perspective. London: Department for Business, Innovation \& Skills. https:/www.gov.uk/government/uploads/system/uploads/attachment_data/file/32484/11 -901-funding-eu-research-innovation-from-2014.pdf (accessed August 4, 2014).

Bleda, M., \& del Rio, P. (2013). The market failure and the systemic failure rationales in technological innovation systems. Research Policy, 42(5), 1039-1052. doi: 10.1016/j.respol.2013.02.008

Cassi, L., Corrocher, N., Malerba, F., \& Vonortas, N. (2008). The impact of EU-funded research networks on knowledge diffusion at the regional level. Research Evaluation, 17(4), 283293. doi: 10.3152/095820208x364535

Chen, Chaomei. (2012). Predictive effects of structural variation on citation counts. Journal of the American Society for Information Science and Technology, 63(3), 431-449. doi: 10.1002/asi.21694

Clarysse, B., Tartari, V., \& Salter, A. (2011). The impact of entrepreneurial capacity, experience and organizational support on academic entrepreneurship. Research Policy, 40(8), 10841093. doi: 10.1016/j.respol.2011.05.010

Costas, R., \& van Leeuwen, T.N. (2012). Approaching the "reward triangle": General analysis of the presence of funding acknowledgments and "peer interactive communication" in scientific publications. Journal of the American Society for Information Science and Technology, 63(8), 1647-1661. doi: 10.1002/asi.22692

Desmarais, Bruce A, \& Harden, Jeffrey J. (2013). Testing for zero inflation in count models: Bias correction for the Vuong test. Stata Journal, 13(4), 810-835.

Didegah, F., \& Thelwall, M. (2013). Determinants of research citation impact in nanoscience and nanotechnology. Journal of the American Society for Information Science and Technology, 64(5), 1055-1064. doi: 10.1002/asi.22806

EPSRC (2014). Funding Guide. Swindon, UK: Engineering and Physical Sciences Research Council. http://www.epsrc.ac.uk/files/funding/how-to-apply/fundingroutes/fundingguide/ (accessed July 31, 2014). 
ERC (2012). Guide for ERC Grant Holders. Final Version, July 2012. Ref. Ares(2012)894501 23/07/2012. Brussels: European Research Council Executive Agency. ftp://ftp.cordis.europa.eu/pub/fp7/docs/erc-guide-grantholders_en.pdf (accessed July 31, 2014).

Etzkowitz, H., \& Leydesdorff, L.A. (1997). Universities and the Global Knowledge Economy: A Triple Helix of University - Industry - Government Relations: Continuum International Publishing Group, Limited.

EU (2012). New Practical Guide to EU Funding Opportunities for Research and Innovation. Annexes. Luxembourg: European Union, CORDIS Publications Office. http://cordis.europa.eu/eu-funding-guide/annex04_en.html\#annexes (accessed August 4, 2014).

Georghiou, L. G., \& Metcalfe, J. S. (1993). Evaluation of the impact of European community research programs upon industrial competitiveness. $R \&$ D Management, 23(2), 161-169. doi: 10.1111/j.1467-9310.1993.tb00083.x

Gibbons, M., Limoges, C., Nowotny, H., Schwartzman, S., Scott, P., \& Trow, M. (1994). The New Production of Knowledge: The Dynamics of Science and Research in Contemporary Societies: Sage.

Greene, W.H. (2003). Econometric Analysis: Pearson Education.

Grupp, H., \& Mogee, M. E. (2004). Indicators for national science and technology policy: how robust are composite indicators? Research Policy, 33(9), 1373-1384. doi: 10.1016/j.respol.2004.09.007

Haslam, N., Ban, L., Kaufmann, L., Loughnan, S., Peters, K., Whelan, J., \& Wilson, S. (2008). What makes an article influential? Predicting impact in social and personality psychology. Scientometrics, 76(1), 169-185. doi: 10.1007/s11192-007-1892-8

Heinze, T., Shapira, P., Rogers, J. D., \& Senker, J. M. (2009). Organizational and institutional influences on creativity in scientific research. Research Policy, 38(4), 610-623. doi: 10.1016/j.respol.2009.01.014

Jennings, M. (2012). Academic output from EU-funded health research projects. The Lancet, 380(9857), 1903. doi: 10.1016/S0140-6736(12)62102-3

Jump, P. (2014). Switzerland downgraded by EU on research involvement. Times Higher Education, February 26. http://www.timeshighereducation.co.uk/news/switzerlanddowngraded-by-eu-on-research-involvement/2011691.article (accessed August 6, 2014).

Katz, J. S., \& Hicks, D. (1997). How much is a collaboration worth? A calibrated bibliometric model. Scientometrics, 40(3), 541-554.

Katz, J. S., \& Martin, B. R. (1997). What is research collaboration? Research Policy, 26(1), 1-18. doi: 10.1016/s0048-7333(96)00917-1

Kleijn, D., \& Sutherland, W. J. (2003). How effective are European agri-environment schemes in conserving and promoting biodiversity? Journal of Applied Ecology, 40(6), 947-969. doi: $10.1111 / \mathrm{j} .1365-2664.2003 .00868 . \mathrm{x}$

Kolodny, H., Stymne, B., Shani, R., Figuera, J. R., \& Lillrank, P. (2001). Design and policy choices for technology extension organizations. Research Policy, 30(2), 201-225. doi: 10.1016/s0048-7333(99)00119-5 
Kostoff, R. N. (1993). Semiquantitative Methods For Research Impact Assessment. Technological Forecasting and Social Change, 44(3), 231-244. doi: 10.1016/00401625(93)90070-n

Kreilkamp, Karl. (1971). Hindsight and the Real World of Science Policy. Science Studies, 1(1), 43-66.

Laredo, P. (1998). The networks promoted by the framework programme and the questions they raise about its formulation and implementation. Research Policy, 27(6), 589-598. doi: 10.1016/s0048-7333(98)00055-9

Lee, Y-G. (2010). Sectoral strategic differences of technological development between electronics and chemistry: a historical view from analyses of Korean-invented US patents during the period of 1989-1992. Scientometrics, 82(1), 83-92. doi: 10.1007/s11192-009-0052-8

Lee, Y-G., Lee, J-D., Song, Y-I., \& Lee, S-J. (2007). An in-depth empirical analysis of patent citation counts using zero-inflated count data model: The case of KIST. Scientometrics, 70(1), 27-39. doi: 10.1007/s11192-007-0102-z

Lewison, G. (1994). Publications from the european-community biotechnology action program (bap) - multinationality, acknowledgment of support, and citations. Scientometrics, 31(2), 125-142.

Lewison, G. (1998). Gastroenterology research in the United Kingdom: funding sources and impact. Gut, 43(2), 288-293.

Lewison, G. (2003). Beyond outputs: new measures of biomedical research impact. Aslib Proceedings, 55(1-2), 32-42. doi: 10.1108/00012530310462698

Lewison, G. (2009). Financial Acknowledgements on the Web of Science: a New Resource for Bibliometric Analysis. In B. Larsen \& J. Leta (Eds.), Proceedings of Issi 2009 - 12th International Conference of the International Society for Scientometrics and Informetrics, Vol 2 (Vol. 2, pp. 968-969). Leuven: Int Soc Scientometrics \& Informetrics-Issi.

Lewison, G., \& Dawson, G. (1998). The effect of funding on the outputs of biomedical research. Scientometrics, 41(1-2), 17-27.

Lewison, G., Grant, J., \& Jansen, P. (2001). International gastroenterology research: subject areas, impact, and funding. Gut, 49(2), 295-302.

Lewison, G., \& Markusova, V. The evaluation of Russian cancer research. Research Evaluation, 19(2), 129-144. doi: 10.3152/095820210x510098

Long, J.S. (1997). Regression Models for Categorical and Limited Dependent Variables: SAGE Publications.

Luukkonen, T. (2012). Conservatism and risk-taking in peer review: Emerging ERC practices. Research Evaluation, 21(1), 48-60. doi: 10.1093/reseval/rvs001

Marin, P. L., \& Siotis, G. (2008). Public policies towards Research Joint Venture: Institutional design and participants' characteristics. Research Policy, 37(6-7), 1057-1065. doi: 10.1016/j.respol.2008.03.007

Martin, S., \& Scott, J. T. (2000). The nature of innovation market failure and the design of public support for private innovation. Research Policy, 29(4-5), 437-447. doi: 10.1016/s00487333(99)00084-0 
Messinis, George. (2011). Triadic citations, country biases and patent value: the case of pharmaceuticals. Scientometrics, 89(3), 813-833. doi: 10.1007/s11192-011-0473-z

Mowery, D. C., Nelson, R. R., \& Martin, B. R. (2010). Technology policy and global warming: Why new policy models are needed (or why putting new wine in old bottles won't work). Research Policy, 39(8), 1011-1023. doi: 10.1016/j.respol.2010.05.008

Mytelka, L. K., \& Smith, K. (2002). Policy learning and innovation theory: an interactive and co-evolving process. Research Policy, 31(8-9), 1467-1479. doi: 10.1016/s00487333(02)00076-8

Nemet, G. F. (2009). Demand-pull, technology-push, and government-led incentives for nonincremental technical change. Research Policy, 38(5), 700-709. doi: 10.1016/j.respol.2009.01.004

Neufeld, J., Huber, N., \& Wegner, A. (2013). Peer review-based selection decisions in individual research funding, applicants' publication strategies and performance: The case of the ERC Starting Grants. Research Evaluation, 22(4), 237-247. doi: 10.1093/reseval/rvt014

Noyons, E., Teigland, R., Schenkel, A., \& Maier, J. (2009). Evaluating a Research Funding Program: Measuring the Impact of EU 6(th) Framework Programme. In B. Larsen \& J. Leta (Eds.), Proceedings of Issi 2009 - 12th International Conference of the International Society for Scientometrics and Informetrics, Vol 1 (Vol. 1, pp. 313-324).

NSF (2001). Grant Proposal Guide. NSF 02-2 (Updated January 2013). Arlington, VA: National Science Foundation. http://www.nsf.gov/pubs/2002/nsf022/nsf022.pdf (accessed July 31, 2014).

Porter, A.L., \& Rafols, I. (2009). Is science becoming more interdisciplinary? Measuring and mapping six research fields over time. Scientometrics, 81(3), 719-745. doi: $10.1007 / \mathrm{s} 11192-008-2197-2$

Rafols, I., Porter, A.L., \& Leydesdorff, L. (2010). Science Overlay Maps: A New Tool for Research Policy and Library Management. Journal of the American Society for Information Science and Technology, 61(9), 1871-1887. doi: 10.1002/asi.21368

Rigby, J. (2009). Comparing the scientific quality achieved by funding instruments for single grant holders and for collaborative networks within a research system: Some observations. Scientometrics, 78(1), 145-164. doi: 10.1007/s11192-007-1970-y

Rigby, J. (2011). Systematic grant and funding body acknowledgement data for publications: new dimensions and new controversies for research policy and evaluation. Research Evaluation, 20(5), 365-375. doi: 10.3152/095820211x13164389670392

Rigby, J. (2013). Looking for the impact of peer review: does count of funding acknowledgements really predict research impact? Scientometrics, 94(1), 57-73. doi: 10.1007/s11192-0120779-5

Rigby, J., \& Julian, K. (2013). Optimizing research impact by allocating funding to researcher grant portfolios: some evidence on a policy option. Paper presented at the International Society for Scientometrics and Informetrics (ISSI) 2013, Vienna, Austria.

Scherngell, T., Roche, I., Horlesberger, M., Besagni, D., Zuger, M. E., \& Holste, D. (2013). Initial comparative analysis of model and peer review process for ERC starting grant proposals. Research Evaluation, 22(4), 248-257. doi: 10.1093/reseval/rvt015 
Shapira, P., \& Wang, J. (2010). Follow the money. What was the impact of the nanotechnology funding boom of the past ten years? Nature, 468, 627-628.

Sherwin, Chalmers W., \& Isenson, Raymond S. (1967). Project Hindsight. Science, 156(3782), 1571-1577. doi: 10.1126/science.156.3782.1571

Sirtes, D. (2013). Funding acknowledgements for the German Research Foundation (DFG). The dirty data of the web of science database and how to clean it up. Paper presented at the International Society for Scientometrics and Informetrics (ISSI) 2013, Vienna, Austria.

Stata. (2011). Stata Base Reference Manual: Release 12: Statacorp Lp.

Thomas, D., \& Nedeva, M. (2012). Characterizing researchers to study research funding agency impacts: The case of the European Research Council's Starting Grants. Research Evaluation, 21(4), 257-269. doi: 10.1093/reseval/rvs020

Upham, S. P., Rosenkopf, L., \& Ungar, L. H. (2010). Positioning knowledge: schools of thought and new knowledge creation. Scientometrics, 83(2), 555-581. doi: 10.1007/s11192-009$0097-8$

van den Besselaar, P., \& Sandstrom, U. (2013). The effect of funding modes on the quality of knowledge production. Paper presented at the International Society for Scientometrics and Informetrics (ISSI) 2013, Vienna, Austria.

Vuong, Quang H. (1989). Likelihood Ratio Tests for Model Selection and Non-Nested Hypotheses. Econometrica, 57(2), 307-333. doi: 10.2307/1912557

Wang, J., \& Shapira, P. (2011). Funding acknowledgement analysis: an enhanced tool to investigate research sponsorship impacts: the case of nanotechnology. Scientometrics, 87(3), 563-586. doi: 10.1007/s11192-011-0362-5

Wang, X.W., Liu, D., Ding, K., \& Wang, X.R. (2012). Science funding and research output: a study on 10 countries. Scientometrics, 91(2), 591-599. doi: 10.1007/s11192-011-0576-6

Whitley, R. (2000). The Intellectual and Social Organization of the Sciences (2nd ed.). Oxford: Oxford University Press.

Yegros-Yegros, A., \& Costas, R. (2013). Analysis of the web of science funding acknowledgement information for the design of indicators on 'external funding attraction.' Paper presented at the International Society for Scientometrics and Informetrics (ISSI) 2013, Vienna.

Yoshikane, Fuyuki. (2013). Multiple regression analysis of a patent's citation frequency and quantitative characteristics: the case of Japanese patents. Scientometrics, 96(1), 365379. doi: 10.1007/s11192-013-0953-4 